\title{
Optimalisasi Guru PAI dalam Merancang Media Pembelajaran
}

\author{
Fani Selviani ${ }^{1}$, Ahmad Syaiful ${ }^{3}$ \\ 1,2 Universitas Islam Negeri Sultan Aji Muhammad Idris Samarinda, Samarinda, Indonesia \\ Samarinda, Indonesia \\ Email: selvifani197@gmail.com (Corresponding Author)
}

\begin{tabular}{|c|c|}
\hline (A) Check for updates open access cc) (i) & DOI: https://doi.org/10.53621/jider.v2i1.115 \\
\hline Informasi Artikel & ABSTRAK \\
\hline $\begin{array}{l}\text { Riwayat Artikel: } \\
\text { Diterima: } 27 \text { Desember } 2021 \\
\text { Revisi: } 23 \text { Januari } 2022 \\
\text { Disetujui: 03 Februari } 2022 \\
\text { Terbit: } 28 \text { Februari } 2022\end{array}$ & $\begin{array}{l}\text { Tujuan dari penelitian ini adalah untuk mengetahui dan menganalisis } \\
\text { bagaimana Optimalisasi Guru PAI Dalam Merancang Media Pembelajaran } \\
\text { berdasarkan pendapat dari mahasiswa Fakultas Tarbiyah dan Ilmu } \\
\text { Keguruan dan untuk mengetahui factor-faktor apa saja yang menghambat } \\
\text { dalam merancang media pembelajaran Guru atau Dosen PAI. Jenis }\end{array}$ \\
\hline $\begin{array}{l}\text { Kata Kunci: } \\
\text { Optimalisasi Guru PAI, } \\
\text { Strategi Pembelajaran, } \\
\text { Media Pembelajaran. }\end{array}$ & $\begin{array}{l}\text { penelitian yang digunakan adalah penelitian menggunakan analisis data. } \\
\text { Sampel penelitian ini berjumlah } 24 \text { responden yang berasal dari mahasiswa } \\
\text { Fakultas Tarbiyah dan Ilmu Keguruan dan pengumpulan data } \\
\text { menggunakan kuisioner. Dari hasil penelitian menunjukan bahwa } \\
\text { Optimalisasi Guru PAI Dalam Merancang Media Pembelajaran di Fakultas }\end{array}$ \\
\hline 回神娄回 & $\begin{array}{l}\text { Tarbiyah dan Ilmu Keguruan telah berkembang mengikuti perkembangan } \\
\text { zaman. }\end{array}$ \\
\hline
\end{tabular}

\section{PENDAHULUAN}

Media pembelajaran merupakan sebuah metode, isi, dan juga teknik yang digunakan untuk menunjang proses pembelajaran agar dapat berjalan dengan baik dan maksimal. Penggunaan metode penelitian haruslah digunakan secara tepat dan disesuaikan dengan materi yang akan di ajarkan. Tidak jarang kita lihat banyak pendidik yang menggunakan media pembelajaran yang tidak sesuai dengan materi yang akan di ajarkan dan ini terkadang membuat siswa tidak dapat memahami materi pembelajaran dengan baik. Jika menggunakan media pembelajaran maka pendidikan yang didapatkan oleh peserta didik dapat di serap dan bermanfaat dengan baik. Dalam Undang-Undang no. 20 Tahun 2003 mengenai Sistem Pendidikan Nasional disebutkan pendidikan ialah usaha sadar dan terencana untuk mewujudkan suasana belajar dan proses pebelajaran agar peserta didik dapat secara aktif mengembangkan potensi dirinya untuk memiliki kekuatan spiritual keagamaan, pengendalian diri, kepribadian, kecerdasan, akhlak mulia, juga keterampilan yang diperlukan untuk diri sendiri, masyarakat, bangsa dan negara (Nasional, 2003).

Menurut Tujo Nurseto dalam kaitan dengan fungsi media pembelajaran, dapat ditekankan beberapa hal sebagai berikut: sebagai alat untuk membuat pembelajaran yang lebih efektif dan efisien, mempercepat proses belajar, meningkatkan kualitas proses belajar mengajar, mengkongkretkan yang abstrak sehingga dapat mengurangi terjadinya penyakit verbalisme. Adapun juga perencanaan dalam pembuatan media meliputi beberapa hal yakni: Identifikasi kebutuhan dan karakteristik siswa, Perumusan tujuan, memilih, merubah dan merancang media pembelajaran, perumusan materi, pelibatan siswa dan evaluasi (Nurseto, 2012).

Kata pendidik berasal dari didik, yang artinya adalah memelihara, merawat dan memberi latihan agar seseorang memiliki ilmu pengetahuan seperti yang diharapkan (mengenai sopan santun, akal budi, akhlak, dan lain sebagainya). Dengan menambahkan awalan pe- sehingga menjadi pendidik yang artinya seorang pendidik. Secara etimologi dalam bahasa inggris terdapat beberapa kata yang mendekati arti pendidik yakni kata tacher yang artinya mengajar dan tutor yang artinya guru pribadi, dipusat pusat pelatihan disebut dengan trainer atau instruktur. Maka, dpaat disimpulkan bahwa orang yang memiliki tanggung jawab dan mempengaruhi jiwa serta rohani seseorang mulai dari segi pertumbuhan jasmani, pengetahuan, keterampilan, serta aspek 
spiritual dalam upaya perkembangan seluruh potensi yang dimiliki oleh seseorang yang sesuai dengan prinsip dan ajaran (Ramli, 2015a).

Tugas pendidik yang utama ialah mengajar atau mendidik, membimbing, mengarahkan, melatih, menilai, mengevaluasi peserta didik dan mendidik murid dikelas maupun diluar kelas. Secara spesifik guru Pendidikan Agama Islam adalah orang yang pekerjaannya mengajarkan pelajaran agama islam. Oleh sebab itu, dapat dijelaskan bahwa guru pendidikan agama islam adalah sosok yang senantiasa mengajarkan materi pelajaran agama islam, tetapi juga mendidik dan menanamkan nilai-nilai yang baik kepada peserta didiknya (Darimi, 2015).

Dalam proses pembelajaran Pendidikan Agama Islam dapat lebih mudah dalam mencari informasi, manipulasi, pengelolaan dan transfer ilmu atau pemindahan informasi, sehingga pengintegrasian TIK dalam proses pembelajaran menjadi peran penting dalam mengembangkan kemampuan berpikir siswa, mengembangkan keterampilan dalam bidang TIK untuk kelancaran proses belajar mengajar, meningkatkan profesional guru dalam penggunaan media TIK khususnya dalam pelajaran PAI, dan mengubah sekolah menjadi institusi pembelajaran kreatif dan dinamis sehingga siswa termotivasi, selalu ingin tahu dalam pembelajaran PAI (Darimi, 2017).

Perkembangan teknologi informasi dewasa dalam dunia hiburan semakin pesat, sehingga anak-anak lebih suka menonton sinetron, film, bermain game, dan menjadikan internet sebagai guru mereka daripada mendengarkan penjelasan guru dikelas. Oleh sebab itu guru terutama guru agama islam dituntut untuk menciptakan pembelajaran yang menarik dan menghibur dengan memasukkan pesan-pesan moral untuk peserta didik. Agar proses pembelajaran yang diciptakan menjadi menarik, maka salah satu yang harus dilakukan oleh tenaga pengajar saat ini adalah mencoba untuk mengmbangkan dan memanfaatkan media pembelajaran yang menarik dalam proses pembelajaran. Adapun media yang harus digunakan sesuai dengan kemajuan Teknologi Pendidikan (Educational Technology), maupun Teknologi Pembelajaran (Instructional Technology) menuntut digunakannya berbagai media pembelajaran (instructional media) serta peralatan-peralatan yang semakin canggih (sophisticated) (Saddam Husein, 2018).

Anderson (1976) mengemukakan adanya dua pendekatan atau model dalam proses pemilihan media pembelajaran, yakni: model pemilihan tertutup dan model pemilihan terbuka. Mengenai jenis media rancangan (by design) terdapat beberapa macam cara yang telah dikembangkan untuk memilih media pembelajaran. Anderson (1976) berpendapat menggunakan prosedur pemilihan media pembelajaran menggunakan pendekatan flowchart (diagram alur). Menurut Anderson (1976) juga media merupakan alat peraga atau perlengkapan yang digunakan untuk membantu guru dalam mengajar (Rusydiyah, 2014).

\section{KAJIAN PUSTAKA}

Menurut Oemar Hamalik media pembelajaran adalah alat, metode dan teknik digunakan dalam rangka lebih mengefektifkan komunikasi dan interaksi antara guru dengan siswa dalam proses pembelajaran disekolah. Sedangkan menurut Suprapto dkk, menjelaskan bahwa media pembelajaran adalah suatu alat pembantu secara efektif yang dapat digunakan oleh guru untuk mencapai tujuan yang diinginkan (Azhar Arsyad, 2011).

Perkembangan media pembelajaran menurut Asbhy seperti yang dikutip oleh Miarso, telah memunculkan empat kali revolusi dalam dunia pendidikan. Revolusi pertama telah terjadi beberapa abad yang lalu, yaitu pada saat orang tua menyerahkan pendidikan anak-anaknya kepada seseorang yang berprofesi sebagai guru; revolusi kedua terjadi dengan digunakannya bahasa tulisan sebagai sarana utama pendidikan; revolusi ketiga muncul dengan tersedianya media cetak yang merupakan hasil ditemukannya mesin teknik percetakan; dan revolusi keempat berlangsung dengan meluasnya penggunaan media komunikasi elektronik (Setiawan, 2019).

Menurut Ahmad Tafsir, Pendidikan Agama Islam (PAI) merupakan bidang Studi Agama Islam (Tafsir, 1995). Pendidikan Agama Islam (PAI) merupakan usaha yang lebih khusus ditekankan untuk mengembangkan fitrah keberagaman subyek peserta didik agar lebih mampu memahami, menghayati dan mengamalkan ajaran-ajaran Islam. Selain itu, Pendidikan Agama Islam tidak hanya sekedar proses usaha mentransfer ilmu pengetahuan atau norma agama tetapi juga berusaha mewujudkan perwujudan jasmani dan rohani dalam peserta didik agar kelak 
menjadi generasi yang memiliki watak, budi pekerti, dan kepribadian yang luhur serta kepribadian muslim yang utuh. Pembelajaran PAI merupakan suatu proses yang bertujuan untuk membantu peserta didik dalam belajar Agama Islam. Pembelajaran ini akan lebih membantu dalam memaksimalkan kecerdasan peserta didik yang dimiliki, menikmati kehidupan, serta kemampuan untuk berinteraksi secara fisik dan sosial terhadap lingkungan (Hanafi, 2019).

Heinich, Molenda dan Russel (1982) dalam bukunya yang berjudul "Intructional Media And The New Rechnologies Of Instructurs" menyusun sebuah model procedural yang diberi nama akronim "ASSURE" model ASSURE ini bertujuan untuk menjamin penggunaan media pembelajaran yang efektif. Model pembelajaran yang diakronimkan dengan ASSURE itu meliputi 6 langkah dalam perencanaan sistematik untuk penggunaan media, yakni: identifikasi kebutuhan dan karakter siswa, perumusan tujuan, memilih, merubah dan merancang media pembelajaran, perumusan materi, pelibatan siswa, dan evaluasi (Nurseto, 2012).

Ely dalam Danim menyebutkan manfaat media dalam pembelajaran yakni: meningkatkan mutu pendidikan dengan cara meningkatkan kecepatan belajar, memberikan kemungkinan pendidikan yang bersifat lebih individual, memberi dasar pengajaran yang lebih ilmiah, pembelajaran dapat dilakukan dengan lebih baik, meningkatkan kedekatan guru dan peserta didik, dan memberikan penyajian pembelajaran yang lebih luas dan menarik. Selain itu, hasil dari penelitian yang dilakukan oleh Ahmad ibn Abd al-Rahman al-Samiraa'I, sebagaimana yang dikutip dari Yasmaruddin, ditemukan bahwa tingkat pencapaian pengetahuan melalui indra penglihatan. Media pembelajaran yang dilengkapi dengan gambar-gambar akan memberikan dampak tiga kali lebih besar dan lebih kuat daripada ceramah. Oleh sebab itu, media pembelajaran yang dapat memadukan kata-kata (suara) dan gambar dapat memberikan peran penting dalam menunjang efektifitas pembelajaran yang dilakukan oleh guru (Mahnun, 2012).

\section{METODE PENELITIAN}

Penulisan ini menggunakan metode penelitian study survey. Data dikumpulkan melalui teknik survei dengan instrumen dalam bentuk kuisioner (Anita Azmi et al., 2020). Kuisioner digunakan untuk mencari tahu opini mahasiswa mengenai optimalisasi guru pai dalam media pembelajaran yang disebarkan menggunakan whatsapp untuk menemukan titik perkembangan dan melihat sejauh mana perkembangan media pembelajaran yang digunakan pendidik dalam pembelajaran PAI. Pada penelitian diberikan 10 pertanyaan untuk mengetahui pendapat responden dan responden yang mengisi angket tersebut sebanyak 24 orang dari mahasiswa/i Universitas Sultan Aji Muhammad Idris Samarinda.

\section{HASIL DAN PEMBAHASAN}

Media pembelajaran yang merupakan teknologi dianggap sebagai aplikasi ilmu pengetahuan dapat berwujud media elektronik atau mesin pembelajaran lainnya yang menempati posisi strategis dalam mempermudah dam memperlancar proses belajar mengajar. Jangkauan belajar juga menjadi lebih luas dan pada akhirnya penerapan teknologi pembelajaran memiliki kontribusi yang besar dalam dunia pendidikan khususnyadalam pendidikan agama islam (Miftah, 2013). Media pembelajaran yang digunakan dalam proses pembelajaran, ada media yang sudah siap untuk digunakan atau dipakai dan ada juga media yang harus dibuat oleh guru, atau dirancang dan dikembangkan oleh guru yang bersangkutan, yang disebut dengan media by design (Ramli, 2015b). Untuk mengetahui hasil penelitian dari Optimalisasi Guru PAI Dalam Merancang Media Pembelajaran akan diuraikan sebagai berikut:

Tabel 1. Optimalisasi Guru PAI Dalam Merancang Media Pembelajaran

\begin{tabular}{|c|c|c|c|c|c|}
\hline No & pertanyaan & iya & $\begin{array}{c}\text { Terkadang } \\
\text { atau } \\
\text { sering }\end{array}$ & Tidak juga & tidak \\
\hline 1. & $\begin{array}{l}\text { Apakah media pembelajaran yang } \\
\text { digunakan dosen FTIK dirasa telah }\end{array}$ & $50 \%$ & $20,8 \%$ & $29,2 \%$ & $0 \%$ \\
\hline
\end{tabular}


efisien.

2. Apakah dari media pembelajaran yang digunakan dosen dapat membuat anda lebih mudah memahami materi yang diajarkan.

3. Apakah media pembelajaran yang digunakan di FTIK dirasa telah mengikuti perkembangan zaman

4. Apakah media pembelajaran yang digunakan di FTIK sudah cukup efisien.

5. Apakah dosen dirasa dapat dengan baik.

6. Media pembelajaran seperti zoom, google classroom apakah membuat anda dapat memahami materi yang di ajarkan dengan cepat.

7. Apakah dosen masih banyak menggunakan metode ceramah $33,3 \%$

$41,7 \%$

$25 \%$

$0 \%$ daripada menggunakan media untuk belajar.

8. Apalah dosen dirasa telah menguasai media pembelajaran debgan baik.

9. Apakah media pembelajaran yang digunakan dosen FTIK dapat mempermudah proses belajar mengajar.

10. Media pembelajaran online pada saat pandemi seperti ini apakah berpengaruh besar pada keaktifan belajar untuk anda.

58,3

$33,3 \%$

$54,2 \%$

$33,3 \%$

$25 \%$

$37,5 \%$

$4,2 \%$

$25 \%$

$58,3 \%$

$50 \%$

$58,3 \%$

$20,8 \%$

$4,2 \%$

$25 \%$

$37,5 \%$

$4,2 \%$

$25 \%$

$20,8 \%$

$0 \%$

$33,3 \%$

$41,7 \%$

$0 \%$

$25 \%$

$16,7 \%$

$0 \%$

$25 \%$

$25 \%$

$0 \%$

$20,8 \%$

$20,8 \%$

$0 \%$

Jika kita lihat dari tabel di atas dapat kita lihat bahwa selain ada kelebihan tentunya juga ada kekurangan entah dari media yang digunakan atau metode dari sang pendidik itu sendiri. Selain itu, jika dilihat dari hasil responden yang berpartisipasi lebih banyak yang mengatakan bahwa media pembelajaran yang digunakan di Universitas Islam Negeri Sultan Aji Muhammad Idris Samarinda digunakan cukup baik dan mempermudah proses pembelajaran. Kelebihannya seperti dapat dianalisis lebih mudah, dapat mengatasi ketratasan ilmu pengetahuan peserta didik, dapat membangun keinginan dan minat belajar peserta didik,mudah untuk diaplikasikan; sedangkan kekurangan dari media pembelajaran itu sendiri seperti kurang praktis dalam penggunaanya, hanya berupa gambaran dan tulisan sehingga tidak dapat diterapan untuk peserta didik yang berkebutuhan khusus, dan biaa produksi cukup mahal dikarenakan ada yang di cetak atau membuat dan mengirimkannya sebelum dinikmati oleh peserta didik.

Dari penelitian yang telah dilakukan di Fakultas Tarbiyah dan Ilmu Keguruan dari para responden ini kita dapat meliat berapa jumlah responden yang menjawab dari pertanyaan pertanyaan tersebut salah satunya seperti apakah dosen dirasa telah menguasai media pembelajaran. 

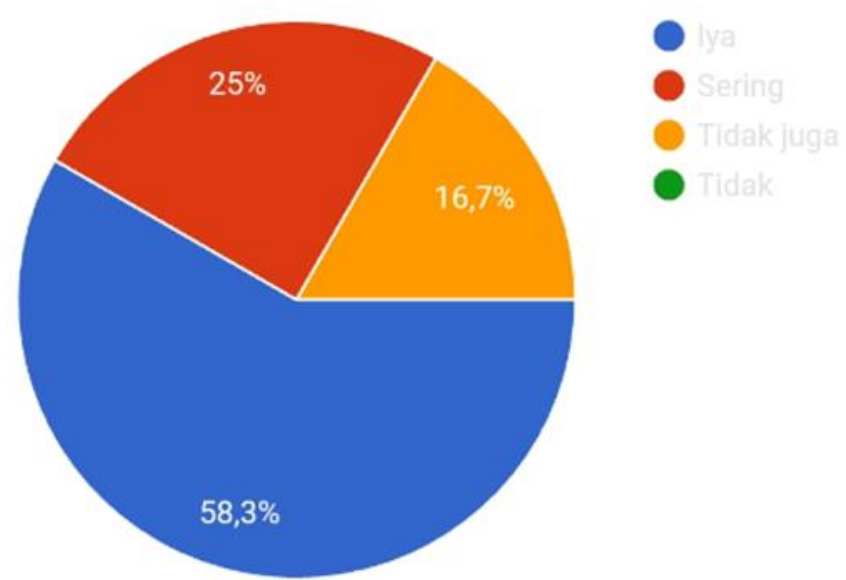

Gambar 1. distribusi responden berdasarkan hasil dari dosen dirasa telah menguasai media pembelajaran

Dari data diatas kitadapa melihat bahwa jumlah responden yang menjawab dosen dirasa telah menguasai media pembelajaran sebanyak $58,3 \%$, jumlah responden yang menjawab dosen sering kurang menguasai media pembelajaran sebanyak $25 \%$, dan jumlah responden yang menjawab dosen tidak terlalu menguasai media pembelajaran sebanyak 16,7\%. Dari hasil diatas dapat kita simpulkan bahwa banyak pendidik yang telah menyesuaikan atau mengikuti perkembangan teknologi dan juga masih ada beberapa pendidik yang masih mencoba untuk mengikuti perkembangan zaman. Jika kita lihat saat ini perkembangan teknologi sangatlah pesat, melalui media pembelajaran dapat membuat proses belajar mengajar lebih efektif dan efisien serta menjadi sebuah penghubung antara pendidik dengan peserta didik (Tafonao, 2018).

Setelah guru PAI mengetahui akan pentingnya belajar teknologi serta aplikasi-aplikasi didalamnya untuk mendukung pembelajaran jarak jauh makaselanjutnya harus mau, karena walaupun guru PAI telah tahu tetapi jika tidak melakukannya maka pembelajaran jarak jauh hanya akan menjadi beban bagi guru dan tentunya tidak tercapai apayang telah direncanakan. Penjelasan tentang beberapa hal yang berkaitan dengan pemanfaatan media dalam pembelajaran adalah untuk mengetahui bagaimana penerapan multimedia tersebut dalam materi PAI agar siswa mencapai taraf penguasaan (Iriani, 2019).

\section{KESIMPULAN}

Media pembelajaran sangatlah penting, suatu keberhasilan sebuah pendidikan ditentukan oleh bagaimanapeserta didik menerima pendidikan dan pembelajaran dalam hidupnya. Media pembelajaran semakin lamasemakin berkembang, pendidikselalu dituntut agar dapat mengikuti perkembangan zaman termasuk guru Pendidikan Agama Islam dan merancang media pembelajaran yang tepat untuk digunakan dalam pembelajaran dan dapat diterima dengan baik oleh peserta didik. Dalam merancang media pembelajaran juga perlu memperhatikan apa dampak dan manfaat yang akan terjadi dikemudian hari. Membuat media pembelajaran semenarik mungin adalah salah satu tugas dari peserta didik agar apa yang di sampaikan dapat tersampaikan dengan baik. Dalam tahap perencanaan multimedia telah terimplementasi, meskipun belum secara keseluruhan dapat dimanfaatkan dengan baik oleh tenaga pendidik. Ketika seorang pendidik dapat menguasai dan menggunakan media pembelajaran dengan baik meskipun dalam keadaan daring maupun tatap muka maka media pembelajaran yang digunakan secara efektif dan efisien maka proses pembelajaran akan belajar dengan baik dan peserta didik dapat memahami materi yang telah diberikan oleh seorang pendidik.

\section{UCAPAN TERIMA KASIH}

Sebagai peneliti saya mengucaokan banyak terimakasih dari para partisipan mahasiswa/I Universitas Islam Negeri Sultan Aji Muhammad Idris Samarinda dan orang-orang disekitar saya yang telah membantu dan mendukung hingga penelitian ini dapat terselesaikan. 


\section{DAFTAR PUSTAKA}

Anita Azmi, R., Rukun, K., Maksum, H., Studi Magister Teknologi, P., \& Teknik, F. (2020). Analisis Kebutuhan Pengembangan Media Pembelajaran Berbasis Web Mata Pelajaran Administrasi Infrastruktur Jaringan. Jipp, 4(2), 303-314. https:/ / ejournal.undiksha.ac.id/index.php/JIPP/article/view/25840

Azhar Arsyad. (2011). Media pembelajaran. Jakarta: PT Raja Grafindo Persada, 36(1), 9-34. Darimi. (2015). Peningkatan kompetensi pedagogik guru PAI dalam pembelajaran. Jurnal MUDARRISUNA, 4(2), 704-719.

Darimi, I. (2017). Teknologi Informasi Dan Komunikasi Sebagai Media Pembelajaran Pendidikan Agama Islam Efektif. Jurnal Pendidikan Teknologi Informasi, 1, 111-121. https:/ / doi.org/10.1007/s11068-008-9037-4

Hanafi, R. H. (2019). Desain Media Pembelajaran Pendidikan Agama Islam Berbasis Aplikasi Android Materi Pengurusan Jenazah Untuk Siswa Kelas XI Sekolah Menengah Kejuruan. Atthulab, 4(1), 99-104.

https://journal.uinsgd.ac.id/index.php/atthulab/article/view/3096/2466

Iriani, F. (2019). Kreativitas Guru Pendidikan Agama Islam dalam Pemanfaatan Media Pembelajaran dan Kemampuan Siswa dalam Memahami Materi PAI di Sekolah Dasar. DAYAH: Journal of Islamic Education, 2(2), 168.

https:/ / doi.org/10.22373/jie.v2i2.4164

Mahnun, N. (2012). media Pembelajaran (Kajian Lengkap Langkah-Langkah Media dan Implementasinya Dalam Pembelajaran. Jurnal Pemikiran Islam, 37(03), 01. https:/ / doi.org/10.4236/ce.2020.113020

Miftah, M. (2013). Fungsi, Dan Peran Media Pembelajaran Sebagai Upaya Peningkatan Kemampuan Belajar Siswa. Jurnal Kwangsan, 1(2), 95. https:/ / doi.org/10.31800/jtpk.v1n2.p95--105

Nasional, D. P. (2003). Undang-Undang RI No. 20 Tahun 2003. Tentang Sisitem Pendidikan Nasional, (Jakarta,:Depratemen Pendidikan Nasional,2003), 1(2), 3.

http:/ / citeseerx.ist.psu.edu/viewdoc/download?doi=10.1.1.88.5042\&rep=rep1\&typ e=pdf\%0Ahttps:/ / www.ideals.illinois.edu/handle/2142/73673\%0Ahttp://www.sc opus.com/inward/record.url?eid=2-s2.0-

33646678859\&partnerID=40\&md5=3ee39b50a5df02627b70c1bdac4a60ba\%0Ahtt

Nurseto, T. (2012). Membuat Media Pembelajaran yang Menarik. Jurnal Ekonomi Dan Pendidikan, 8(1), 19-35. https:/ / doi.org/10.21831/jep.v8i1.706

Ramli, M. (2015a). Hakikat pendidikan dan peserta didik. Tarbiyah Islamiyah, 5(1), 61-85. https:/ /jurnal.uin-antasari.ac.id/index.php/tiftk/article/view/1825

Ramli, M. (2015b). Rancangan Media Pembelajaran Pendidikan Agama Islam. Tarbiyah Islamiyah, 5(2), 56-78. https:/ / doi.org/10.18592/tiftk.v5i2.755

Rusydiyah, E. F. (2014). Merancang Media Pembelajaran PAI yang Menarik (Analisis Pemikiran Anderson). Al-Fitrah, 9(1). http:/ / ejournal.iainjember.ac.id/index.php/alfitrah/article/view/296

Saddam Husein, S. U. M. S. S. (2018). Urgensi Media Dalam Proses Pembelajaran. AlIltizam: Jurnal Pendidikan Agama Islam, 3(2), 237.

https:/ / doi.org/10.33477/alt.v3i2.605

Setiawan, A. (2019). Merancang Media Pebelajaran PAI Di sekolah ( Analisis Implementasi Media Pembelajaran Berbasis PAI ). 10, 223-240.

Tafonao, T. (2018). Peranan Media Pembelajaran Dalam Meningkatkan Minat Belajar Mahasiswa. Jurnal Komunikasi Pendidikan, 2(2), 103.

https:/ / doi.org/10.32585/jkp.v2i2.113 